\title{
Transient sensations of impending loss of consciousness: the "blip" syndrome
}

\author{
James W Lance
}

\begin{abstract}
Momentary sensations of impending loss of consciousness may occur, particularly when a person is relaxed, without any obvious cardiac, cerebral vascular, or epileptic basis. These episodes may be a quasiepileptic phenomenon such as déjà vu and night starts and seem to have a benign prognosis.
\end{abstract}

$(\mathcal{F}$ Neurol Neurosurg Psychiatry 1996;60:437-438)

Keywords: presyncope; "blip" syndrome

Five years ago I experienced unusual sensations like a shock in the head as though one might be about to lose consciousness. These were momentary and frightening but were not associated with any physical impairment. They recurred several times a week when relaxing or driving a car, persisted for about six months, then disappeared never to return. I recognised that they were not associated with any cardiac dysrhythmia as I have been aware of having extrasystoles in the past, without any such accompaniment. Since then I have encountered a similar symptom in some of my patients, often added apologetically after I had taken the case history of their main complaint as though they felt rather foolish in even mentioning it. It was only when a patient presented to me with this sensation as his chief concern that I wrote a letter to the Medical fournal of Australia ${ }^{1}$ describing it as the "blip" syndrome, a term implying an undesirable transient phenomenon like an artefact on an oscilloscopic tracing. This publication led to correspondence with doctors who had encountered the problem in their patients and three doctors who had experienced the sensation themselves. From these replies and descriptions given to me by my own patients, I have been able to compile this brief report based on 12 case histories, my own not being included.

\section{Details of patients}

AGE AND SEX

The age of the patients at the time of presentation ranged from 33 to 75 years. Four were in their $30 \mathrm{~s}$, two in their $40 \mathrm{~s}$, four in their $60 \mathrm{~s}$, and two in their 70s. Four were men and eight were women.

\section{HISTORY}

The symptoms had been present for periods of two months up to five years. One patient, a 68 year old doctor, stated that she had been subject to these attacks four years ago but they had stopped as suddenly as they had started.

\section{FREQUENCY OF EPISODES}

The attacks usually occurred from one to four times a month but five patients had had two or more episodes in a day, and one had experienced 12-15 attacks daily on some occasions.

\section{DURATION OF EPISODES}

Patients estimated that each attack lasted from "a split second" up to two seconds.

\section{Descriptions}

A woman aged 33 said that the sensation caught her unawares like a shock that sometimes made her jump. Her mind seemed to go blank for a second with a sudden sense of pressure in her forehead. She supported her head with her hands and hung on to a nearby object because she felt as though she could lose balance or faint.

A 35 year old doctor stated that the episodes consisted of "a very brief sensation of impending loss of consciousness". He wrote: "Initially they concerned me although I would not describe them as frightening. The sensation produced seems like one might experience with a sudden cardiac dysrhythmia which limits blood flow to the brain. Checking my pulse at such times reveals no arrhythmia".

A 36 year old woman called them "split second spells like a wave going through me".

A woman aged 37 said that they were like a sudden sensation of movement in the head lasting a fraction of a second.

A woman aged 40 described a sensation of "the brain turning over" as though she could lose consciousness. "Occasionally it was associated with a feeling of being displaced to one side.

A woman aged 60 said that her very brief sensations of light headedness were like "a short circuit in the brain".

A doctor aged 67 wrote of " a horrible feel- 
ing of impending doom" followed shortly by a transient giddy feeling that left her quite shaken.

The remainder simply described a momentary sensation as though they were about to faint.

\section{Precipitating factors}

Most patients said that the attacks tended to occur when they were relaxing, reading, listening to music, or watching television. One mentioned that she had an attack while lying in bed and that another had awakened her from sleep. She had also had episodes while walking or otherwise active, but another woman said that she had never noticed an attack while playing golf or tennis. Only one patient associated the onset of the symptom with a stressful period of her life. Two patients commented on attacks happening while they were driving a car but their ability to drive was unimpaired.

\section{Associated conditions}

Three of the subjects were hypertensive. Four of the group had had migraine, preceded by a visual aura in three. One, a woman of 67 years, was still having frequent episodes of visual aura without headache. One patient developed anxiety symptoms when in a crowd or confined space. One 70 year old patient had had a coronary bypass operation for the relief of angina pectoris and had controlled atrial fibrillation. One patient whom I have not examined had been diagnosed in Holland as having primary lateral sclerosis three years before her episodes developed.

\section{Investigations}

Electroencephalograms (six patients), CT of the brain (five patients), ECG (three patients), Holter monitoring (one patient), and vestibular tests (one patient) were normal. Duplex
Doppler ultrasound studies of the carotid and vertebral arteries in the neck were normal in three patients and showed less than $20 \%$ stenosis of both internal carotid arteries in a 75 year old woman. No investigations were undertaken in five patients.

\section{Discussion}

Possible causes of the "blip" syndrome include ventricular ectopic beats or other cardiac dysrhythmias, transient ischaemic attacks, and epilepsy. One patient, a 70 year old retired surgeon, had controlled atrial fibrillation without any perceptible change in rhythm at the time of his episodes. No patient had noticed any palpitations or other indication of unusual cardiac rhythm in association with their attacks; three of the 12 patients reported were doctors who had paid particular attention to this aspect. None of the patients reported other neurological symptoms suggestive of carotid or vertebrobasilar insufficiency. Six of the 12 patients were under the age of 50 years and four of the six patients over that age did not have an appreciable degree of vascular disease shown by duplex Doppler ultrasound studies. None of the patients had other manifestations of epilepsy; the EEGs of six were normal and the symptoms tended to remit spontaneously.

The mechanism of these transient attacks remains uncertain. They may represent a quasiepileptic phenomenon such as déjà vu, night starts, and "exploding head syndrome," 2 experienced by many normal people. Simultaneous EEG and ECG monitoring would be a worthwhile undertaking in any patients experiencing many such episodes each day to see if this helps to elucidate the cause. In the meantime, patients may be reassured that these "blips" seem to be a benign phenomenon.

1 Lance JW. The blip syndrome. Med $\mathcal{f}$ Aust 1994;160:585. 270-1. 